\title{
An assessment of the quality of various brands of paracetamol tablets sold in the Nigerian capital city
}

\author{
Enoche Florence OGA ${ }^{1 *}$, Florence D. TARFA ${ }^{1}$ and Olayinka JOLAOSHO ${ }^{1}$ \\ ${ }^{1}$ Medicinal Chemistry \& Quality Control Department,National Institute for Pharmaceutical Research \& \\ Development, PMB 21, Garki, Abuja. Nigeria. \\ * Corresponding author, E-mail: enocheoga@yahoo.com, Tel: 234-807 3501659
}

\begin{abstract}
To assess the seriousness of the global counterfeiting problem, we quantified the amount of active ingredient present in paracetamol tablets by various official and non-official methods. Eight brands of Paracetamol 500mg tablets were assessed using the quality control parameters of weight uniformity, active ingredient content, thin layer chromatography profile, disintegration tests and visual inspection. The results were subjected to statistical analysis using GraphPad PRISM. One-way analysis of variance (ANOVA) was used to examine differences between the different brands of paracetamol with Dunnett Multiple Comparisons post test analysis. In all cases, $P$ value of $<0.05$ was regarded as statistically significant. The results indicated that $75 \%$ (A, B, C, F, G, H) passed the disintegration tests, $50 \%$ (A, B, D, F) fell within the pharmacopoeial standard for active ingredient content, all the brands complied with the weight variation test, identification tests, as well as falling within the Rf range on TLC spotting in comparison with the reference standard. The cumulative compliance to all of the tests for labelling, visual inspection, disintegration, presence of active ingredient, right quantity of active ingredients, and absence of contaminant spots was $37.5 \%$. Constant monitoring with the view to check counterfeiting of medicines and compliance to required standards is emphasized.
\end{abstract}

(C) 2010 International Formulae Group. All rights reserved.

Keywords: Drug quality control, counterfeit medicines, paracetamol tablets, analgesic.

\section{INTRODUCTION}

Pain is one of the most common of symptoms, and one of the most frequent reasons why people seek medical care (Grichnik and Ferrante, 1991). It is not surprising therefore, that analgesics are among the most widely used categories of drugs (Holland et al., 1998).

Paracetamol is thought to be the most widely used over-the-counter analgesic in the world. It is commonly used for the relief of fever, headaches, and other minor aches and pains, and is a major ingredient in numerous cold and flu remedies. In combination with non-steroidal anti-inflammatory drugs and opioid analgesics, paracetamol is used also in the management of more severe pain (such as cancer or postoperative pain). It is the active metabolite of phenacetin, once popular as an analgesic and antipyretic in its own right, but unlike phenacetin and its combinations, paracetamol is not considered to be carcinogenic at therapeutic doses. Paracetamol acts by reducing production of prostaglandins, 
which are involved in the pain and fever processes, by inhibiting the cyclooxygenase enzyme. Several official and non-official methods for the determination and quantitation of Paracetamol in tablet formulation have been described. These include ultraviolet-visible spectroscopy, near infra red spectroscopy, HPLC, Thin Layer Chromatography, chemiluminiscence (Roy et al., 1997; GPHF, 1998; Alapont et al., 1999; Olaniyi, 2000; Altun, 2002; British Pharmacopoeia, 2004; Shek et al., 2006; Gandhi et al., 2008; Wadher et al., 2008; Buddha and Raja, 2009).

The proliferation of counterfeit and poor-quality drugs is a major public health problem; especially in developing countries lacking adequate resources to effectively monitor their prevalence. Currently, there are no reliable statistics on the level of incidence of fake drugs in Nigeria. Estimates of the extent of counterfeit medicines in circulation in Nigeria ranged from $25 \%$ to $80 \%$ from various studies before 2001. (Shakoor et al., 1997; Erhun et al., 2001; Akunyili, 2006; Morris and Stevens, 2006; Burns, 2006; WHO, 2007).

From a public health point of view, counterfeit/substandard paracetamol may lead to a great health risk. Adverse effects including liver damage, through excessive dose or due to the presence of potentially toxic ingredients or metabolites are not uncommon. When medicines containing little or no active ingredients whether counterfeit or substandard are used for the treatment of common ailments with a high untreated mortality then morbidity and mortality will be on the increase. There is also an increased risk of resistance and as such; therapeutic failure. Counterfeiting also leads to huge financial losses for the pharmaceutical industry and erodes confidence in health-care systems.

This study is carried out to assess the incidence of counterfeiting (if any) of paracetamol tablets on sale in pharmacies within the Nigerian capital, Abuja according to the World Health Organization's standards based on among others, methods in the German Pharma Health Fund (1998) and the British Pharmacopoeia.

\section{MATERIALS AND METHODS \\ Materials}

Volumetric flasks, conical flasks, measuring cylinders, mortar, pestle, aluminum foil, pipettes, laboratory glass bottles, microcapillary tubes, development chamber for TLC, Whatman No 4 filter paper, Glass funnel, $10 \times 20 \mathrm{~cm}$ chromatography plates, Ethanol $75 \% \mathrm{v} / \mathrm{v}$, Acetone, Methanol, Toluene, Glacial acetic acid, $0.1 \mathrm{~N} \mathrm{NaOH}$, $\mathrm{FeCl}_{3}$, distilled water, Jenway 6505 Ultraviolet/Visible Spectrophotometer with matched cuvettes.

Eight brands of paracetamol tablets were purchased from pharmacies within Abuja, Nigeria. The samples were designated A-H accordingly. Pure sample of paracetamol was kindly donated by a research colleague.

\section{Methodology \\ Weight uniformity test}

20 tablets in each group of tablets were weighed individually $(\mathrm{x})$ and also collectively and the weight recorded $\left(\sum x\right)$. The mean, of each group was then calculated and $5 \%$ of the mean was calculated. The weight variation was then calculated as Mean $\pm 5 \%$ of the mean. If two tablets out of 20 are outside the range, the tablets were considered to have failed the weight variation test. The tablets were then crushed into powder and stored in airtight containers.

\section{Simple Disintegration test}

$15 \mathrm{ml}$ of de-ionized water was transferred into a $50 \mathrm{ml}$ beaker and heated to $37{ }^{\circ} \mathrm{C}$ on a water bath and also maintained at that same temperature. One tablet of each paracetamol group was then dropped at the centre of the beaker and allowed to disintegrate without stirring. The tablets were 
then timed from the time they were dropped into the beaker to the time they completely disintegrated. All the tablets were expected to dissolve within $30 \mathrm{~min}$ and those that did not were considered to have failed the test.

\section{Identification test}

For each sample, an amount of the powdered sample expected to contain $0.500 \mathrm{~g}$ of paracetamol was weighed. It was shaken with $20 \mathrm{ml}$ of hot ethanol $(75 \% \mathrm{v} / \mathrm{v})$ and filtered. The filtrate was then evaporated to dryness. $0.1 \mathrm{~g}$ of the dried residue from above was weighed from each sample, mixed with $10 \mathrm{ml}$ of water and $0.5 \mathrm{ml}$ of $25 \% \mathrm{w} / \mathrm{v} \mathrm{FeCl}_{3}$. An intense blue colouration indicated the presence of paracetamol.

\section{TLC Chromatography}

For each of the brands analysed, the average weight of each sample of crushed paracetamol tablets expected to contain 500 $\mathrm{mg}$ of paracetamol was weighed. This was dissolved in $12.5 \mathrm{ml}$ of methanol and shaken for 3 min after which it was allowed to settle. $1 \mathrm{ml}$ of the supernatant above was then transferred into $7 \mathrm{ml}$ of methanol. After which $1 \mathrm{ml}$ of this second solution was transferred into $3 \mathrm{ml}$ of methanol to give a concentration of $1.25 \mathrm{mg} / \mathrm{ml}$. This was also done using 500 $\mathrm{mg}$ of the pure paracetamol sample, after which spotting was done on normal chromatography plates with $13 \% \mathrm{CaSO}_{4}$ as binder and developed in a mobile phase of 40 $\mathrm{ml}$ Acetone: $40 \mathrm{ml}$ Toluene: $1.48 \mathrm{ml}$ Glacial acetic acid. The plates were viewed under UV lamp at $365 \mathrm{~nm}$ and also in an iodine tank. The spots as well as the Rf values were noted.

\section{Paracetamol tablets assay}

$150 \mathrm{mg}$ of paracetamol chemical reference standard was weighed out. It was then added to $50 \mathrm{ml}$ of $0.1 \mathrm{M} \mathrm{NaOH}$ and diluted with $100 \mathrm{ml}$ of de-ionized water and shaken for $15 \mathrm{~min}$ in a $250 \mathrm{ml}$ volumetric flask. $50 \mathrm{ml}$ of water was then added and the solution filtered. $10 \mathrm{ml}$ of the filtrate was made up to $100 \mathrm{ml}$ with water. $10 \mathrm{ml}$ of the resulting solution was then added to $10 \mathrm{ml}$ of
$0.1 \mathrm{M} \mathrm{NaOH}$ and made up to $100 \mathrm{ml}$ with water. The content was appropriately diluted and required aliquots were taken for the preparation of the calibration curve. The absorbance of the resulting solution was then read at $257 \mathrm{~nm}$.

For each brand analysed, the paracetamol tablets were weighed out and powdered. A powdered sample equivalent to $250 \mathrm{mg}$ of paracetamol was accurately weighed out and exactly same process was carried out as above for the chemical reference. The absorbance was measured at $257 \mathrm{~nm}$ and paracetamol was estimated from the calibration curve.

\section{Visual examination}

This involved an inspection of the following parameters; shape (circular, oval, flat sides, other), uniformity of shape, uniformity of colour, no physical damage (cracks, breaks, abrasions, sticky), other observations (no foreign contaminant, dirty marks, proper seal). The basic tests conducted were weighted based on WHO categorization of genuine, substandard and counterfeit medicines.

\section{Statistical Analysis}

The tests were done in triplicates. The data yield was analysed by GraphPad PRISM 5 for Windows, Version 5.02. (GraphPad Software Inc., USA). One-way Analysis of Variance (ANOVA) was used to examine differences between the different brands of paracetamol with Dunnett Multiple Comparisons post test analysis. In all cases, $P$ value of $<0.05$ was regarded as statistically significant.

\section{RESULTS}

Eight brands of paracetamol tablets manufactured in Nigeria were analysed in this study. All samples were within shelf life at the time of the study. They were all registered with the Nigerian regulatory agency, NAFDAC (Table 1). Some visual inspection parameters like uniformity of shape, 
uniformity of colour, presence of physical damage (cracks, breaks, abrasions, sticky), other observations (foreign contaminants, dirty marks, proper seal) and labelling requirements were defective. Two brands, C and $\mathrm{D}$ had no manufacturing dates on their labels. Other requirements of expiry date, batch number and the NAFDAC number were in place. Results of assessment of the simple disintegration test showed a range of 2.58 minutes to over 180 minutes. The disintegration time for $25 \%$ of the analysed brands were outside the GPHF range for the simple disintegration test (>30 min). Brands D and $\mathrm{E}$ failed the test. For the absolute drug content, all samples had label claims of 500 $\mathrm{mg}$ active pharmaceutical ingredient. The British Pharmacopoeia (2004) specifies a range of $90-110 \%$ of Paracetamol in the tablet formulation. The content of paracetamol in four brands (A, B, D and F) was within the pharmacopoeial range. Brands $\mathrm{C}$ and $\mathrm{E}$ were beyond the pharmacopoeial range with values of $112.32 \%$ and $113.94 \%$ respectively while Brands $\mathrm{G}$ and $\mathrm{H}$ had slightly lower values of $89.13 \%$ and $89.95 \%$ respectively. Brands C, D, E, F, G and $\mathrm{H}$ showed statistically significant $(P<0.05)$ differences, while $\mathrm{A}$ and $B$ were non significant. For the weight variation test, the British Pharmacopoeia specifies that not more than two of the individual weights should deviate from the average weight by more than $5 \%$, and none should deviate by more than $10 \%$. From Table 2 , it is observed that Brand $\mathrm{G}$ weighed highest $(0.6163 \pm 0.0308 \mathrm{~g})$ while brand $\mathrm{F}$ weighed least $(0.5402 \pm 0.0270 \mathrm{~g}) .100 \%$ passed the weight variation tests. This test is important especially where the drug substance forms the greater part of the tablet mass as dosage is obviously linked with tablet weight, and a compliance with this standard helps to ensure that uniformity of dosage is achieved. The inter batch weights differences could be attributed to the variations in percentage of excipients especially diluents or bulking agents, which is usually the decision of the formulation pharmacist. Thin Layer Chromatography is of importance for the verification and identification of medicinal products. It is also used to decide on the presence or absence of impurities or degradation products. From Table 2, the Rf for the reference standard was 0.7067. All samples were within the range of the $\mathrm{Rf}$ value \pm 0.1 . One sample however showed two spots of 0.7267 and 0.8667 . This suggests a further need for impurity profiling for the sample.

For all the criteria assessed, only Brands A, B and F representing 37.5\% of the brands assessed passed all the parameters of visual inspection, simple disintegration tests, labelling inspection, presence of active ingredient, right quantity of active ingredient and absence of contamination spots.

\section{DISCUSSION}

Visual inspection of a drug and its packaging is usually an initial indication of the genuineness of the medicament. Labelling is also a critical parameter assessed for in pharmaceuticals as the patients' safety is may be dependent on the label of the medication. Other labelling requirements of expiry date, batch number and regulatory authority registration number (National Agency for Food and Drug Administration and Control, NAFDAC number in Nigeria) are required.

Tablets are required to be sufficiently hard to withstand handling without crumbling or breaking and also sufficiently soft for easy disintegration in the stomach or intestine in order to make the drug available to the body. In this study, the simple disintegration test recommended by the GPHF for mainly for on-the-field assessment and resource poor settings is adopted. It requires that uncoated tablets disintegrate within 30 minutes.

Eight brands of paracetamol $500 \mathrm{mg}$ tablets were assessed using the quality control parameters of weight uniformity, active ingredient content, thin layer chromatography 
Table 1: Labelling description of analysed paracetamol tablets.

\begin{tabular}{lllll}
\hline Sample code & Man. Date & Expiry date & Batch No. & NAFDAC Reg. No. \\
\hline A & $03 / 09$ & $03 / 14$ & $1688 \mathrm{~N}$ & $04-0411$ \\
\hline B & $11 / 08$ & $10 / 13$ & IY1446 & $04-0633$ \\
\hline C & $* *$ & $11 / 11$ & PI7061 & $04-5269$ \\
\hline D & $* *$ & $01 / 12$ & TA34138 & $04-6362$ \\
\hline E & $02 / 08 / 08$ & $02 / 07 / 11$ & M-6488 & $04-2238$ \\
\hline F & $11 / 07$ & $11 / 11$ & PK50 & $04-2116$ \\
\hline G & $01 / 07$ & $01 / 10$ & 7101 & $04-3500$ \\
\hline H & $05 / 09$ & $05 / 12$ & D4IM & $04-0205$ \\
\hline$* *=$ Information not stated on label & & & \\
\hline
\end{tabular}

Table 2: Physicochemical characteristics assessed.

\begin{tabular}{lllll}
\hline Code & $\mathbf{D}_{\mathbf{T}}(\mathbf{m i n})$ & $\mathbf{W}(\mathbf{R})$ & $\mathbf{D C}(\mathbf{P C})$ & $\mathbf{R f}$ \\
\hline $\mathbf{A}$ & 4.52 & $0.5472 \pm 0.0274(0)$ & $542.10(108.42)$ & 0.7067 \\
$\mathbf{B}$ & 6.02 & $0.5973 \pm 0.0299(1)$ & $510.85(102.17)$ & 0.7133 \\
$\mathbf{C}$ & 2.58 & $0.6057 \pm 0.0303(0)$ & $561.60(112.32)$ & 0.6867 \\
$\mathbf{D}$ & 47 & $0.5689 \pm 0.0285(0)$ & $460.15(92.03)$ & 0.6667 \\
$\mathbf{E}$ & $>180$ & $0.5598 \pm 0.0280(0)$ & $569.70(113.94)$ & 0.6467 \\
$\mathbf{F}$ & 16 & $0.5402 \pm 0.0270(0)$ & $458.35(91.67)$ & 0.6933 \\
$\mathbf{G}$ & 4.55 & $0.6163 \pm 0.0308(0)$ & $445.65(89.13)$ & $0.7267,0.8667$ \\
$\mathbf{H}$ & 4 & $0.5794 \pm 0.0290(0)$ & $449.25(89.85)$ & 0.7200 \\
$\mathbf{R e f}$ & & & & 0.7067 \\
\hline
\end{tabular}

$\mathrm{W}=$ Mean Tablet Weight, $\mathrm{D}_{\mathrm{T}}=$ Mean Disintegration time, $\mathrm{PA}=$ Percentage of Label Claim, $\mathrm{R}=$ Number of tablets outside range, $\mathrm{DC}=$ Drug Content, $\mathrm{Rf}=$ Retention factor. 
profile, disintegration tests and visual inspection. The results indicated that $75 \%$ (A, $\mathrm{B}, \mathrm{C}, \mathrm{F}, \mathrm{G}, \mathrm{H})$ passed the disintegration tests, $50 \%$ (A, B, D, F) fell within the pharmacopoeial standard for active ingredient content. This suggests an implication of counterfeiting as the label claims and the actual active drug content differ for $50 \%$ of the samples. This may result in underdosing or overdosing of the medicament and for paracetamol in particular may increase morbidity or mortality as liver damage may occur. All the brands complied with the weight variation test, identification tests, as well as falling within the $\mathrm{Rf}$ range in comparison with the reference standard. The cumulative compliance to all of the tests for labelling, visual inspection, disintegration, presence of active ingredient, right quantity of active ingredients, and absence of contaminant spots was $37.5 \%$.

\section{Conclusion}

As frequently stated, it is worthy to reiterate that pharmaceutical companies and their products should be closely monitored to ensure that every product reaching to the final consumer is of optimal quality. It is observed that all eight brands analyzed had NAFDAC registration numbers, a seal that indicates an approval of the medication for use in Nigeria. It is known that the presence of registration number on a product in Nigeria may not serve as a full guarantee on its overall quality until its quality assurance is done as faking of even registration numbers have been reported.

\section{REFERENCES}

Ajibola A. Olaniyi. 2000. Chemical and Physicochemical Methods: Principles of Drug Quality Assurance and Pharmaceutical Analysis. Ibadan; 179182.

Akunyili D. 2006. Lessons from Nigeria: The fight against counterfeit drugs in Africa. Diabetes Voices, 51(3): 41-43.
Alapont A. Gregorio, Lahuerta Zamora L, Martínez Calatayud J. 1999. Indirect determination of paracetamol in pharmaceutical formulations by inhibition of the system luminol- $\mathrm{H}_{2} \mathrm{O}_{2}-$ $\mathrm{Fe}(\mathrm{CN})_{6}{ }^{3-}$ Chemiluminescence. Journal of Pharmaceutical and Biomedical Analysis, 21(2): 311-317.

Altun ML. 2002. HPLC Method for the Analysis of Paracetamol,Caffeine and Dipyrone. Turk J Chem., 26: 521 - 528.

British Pharmacopoeia. 1998. Her Majesty's Stationery Office. Vol 1. London, pp. 994-995.

Buddha RS, Raja RP. 2009. Spectrophotometric method for the determination of paracetamol. J. Nepal Chem. Soc., 24:39-44.

Burns W. 2006. WHO launches taskforce to fight counterfeit drugs. Bulletin of the World Health Organization., 84(9): 685764.

Erhun WO, Babalola OO, Erhun MO. 2001. Drug Regulation and Control in Nigeria: The Challenge of Counterfeit Drugs. Journal of Health and Population in Developing Countries, 4(2): 23-34.

Gandhi SV, Barhate NS, Patel BR, Pancha DD, Bothara KG. 2008. A validated densitometric method for analysis of aceclofenac and paracetamol as the bulk drugs and in combined tablet dosage forms. Acta Chromatographica, 20(2): $175-182$.

GPHF (German Pharma Health Fund). 1998. A Concise Quality Control Guide on Essential Drugs and Other Medicines: Manual Accompanying the GPHF Minilab. Thin Layer Chromatograhy Vol II. Germany. pp 9-12, 94-97.

Grichnik KP, Ferrante FM. 1991. The difference between acute and chronic pain. Mount Sinai Journal of Medicine, 58(3): 217-220.

Holland AJA, Jackson SHD, Turner P. 1998. A survey of analgesic drug utilisation 
within and between clinical units in a health District. International Journal of Clinical Pharmacology, Therapy and Toxicology, 26(9): 465-467.

Morris J, Stevens P. 2006. Counterfeit Medicines in Less Developed Countries: Problems and Solutions. International Policy Network: London; 1-9.

Roy J, Saha P, Sultana S, Kenyon AS. 1997. Rapid screening of marketed paracetamol tablets: use of Thin Layer Chromatography and a Semi Quantitative Spot Test. WHO Bulletin., 75(1): 19-22.

Shakoor O, Taylor R, Behrens R. 1997. Assessment of the incidence of substandard drugs in developing countries. Tropical Medicine \& International Health. 2(9): 839-845.
Shek YHM, Jee RD, Moffat AC. 2006. The identification of counterfeit and substandard paracetamol tablets by nearinfrared spectroscopy. Journal of Pharmacy and Pharmacology, 58(10): 8.

Wadher SJ, Pathankar PR, Manisha Puranik, Ganjiwale RO, Yeole PG. 2008. Simultaneous spectrophotometric estimation of paracetamol and metoclopramide hydrochloride in solid dosage form. Indian Journal of Pharmaceutical Sciences. 70(3): 393-395.

WHO (World Health Organisation). 2007. Counterfeit medicines: an update on estimates. News Release WHO/7. 13 March 2007. Accessed on 21 August 2009 at http://www.istm.org/publications/ news_share/200805/counterfeit.aspx 